\title{
PostScript
}

LETTERS

If you have a burning desire to respond to a paper published in the JECH, why not make use of our "rapid response" option?

Log on to our website (www.jech.com) find the paper that interests you, and send your response via email by clicking on the "eletters" option in the box at the top right hand corner

Providing it isn't libellous or obscene, it will be posted within seven days. You can retrieve it by clicking on "read eletters" on our homepage.

The editors will decide as before whether to also publish it in a future paper issue.

\section{No place for modesty}

"A leader is best when people barely know he exists, not so good when people obey and acclaim him, worse when they despise him.. But of a good leader who talks little when his work is done, his aim fulfilled, they will say, "We did it ourselves."

Clearly John Ashton's aphorism mirrors Lao Tzu's thoughts on leadership, and is thus hard to argue against. ${ }^{1}$ However, I think public health practitioners should indeed be "bothered... if we don't get the credit for our own ideas." It is precisely this self effacing stance that has led to the current situation where public health is grossly undervalued and under-resourced. It is hard enough trying to promote a negative-the disease outbreak that didn't happen-we only make it worse for ourselves if we allow others to claim responsibility for all the visible successes.

Why should public health practitioners be employed if the successes are due to the "exertions" of politicians and generic bureaucrats? It is time that we assembled the evidence of our many successes and market public health and its practitioners aggressively. We need to attract the attention of those who procure sickness services at ever increasing expense and show them the folly of neglecting the protectors, promoters, and the preventers. Time to dispense with the bushel and let our lights shine!

C R Douglas

Australasian Faculty of Public Health Medicine PO Box S1296 Perth, WA 6845, Australia charles.douglas@health.wa.gov.au

\section{Reference}

Ashton JR. "Success has 100 parents, failure is an orphan". J Epidemiol Community Health 2003;57:646

\section{Standardised QALYs and DALYs are more understandable, avoid misleading units of measurement, and permit comparisons}

QALYs and DALYs combine years of life and quality of life in a single measure. ${ }^{1-3}$ In Arnesen and Nord's words: "DALYs and QALYs are complementary concepts. QALYs are years of healthy life lived; DALYs are years of healthy life lost. Both approaches multiply the number of years ( $x$ axis) by the quality of those years (y axis). QALYs use "utility weights" of health states; DALYs use "disability weights" to reflect the burden of the same states. For example, if the utility of deafness is 0.67 , the disability weight of deafness is $1-0.67=0.33$. Disregarding age weighting and discounting, and assuming lifetime expectancy of 80 years, a deaf man living 50 years represents $0.67 \times 50=33.5$ QALYs gained and $0.33 \times 50+1.0 \times(80-50)$ $=46.5$ DALYs lost". ${ }^{\prime 2}$ We can see that $33.5+46.5=80.0$ - that is, QALYs+DALYs $=$ lifetime expectancy.

If we would like to be more accurate, we had to put QALYs $=0.67 \times 50 \mathrm{y}=33.5 \mathrm{y}$ and DALYs $=0.33 \times 50 y+1.0 \times(80 y-30 y)=46.5 y$. This means that the unit of measurement of QALYs and DALYs is years (y). As y is the unit of measurement of lifetime, using the same unit for the product "lifetime $\times$ lifequality" is confusing

Saying that quality is rated on a scale from 0 to 1 , we, in fact, have implicitly transformed the real but unknown scale of quality into a standard scale, where 0 denotes no quality at all and 1 the $100 \%$ o quality expected (lifequality expectancy). Therefore, QALYs and DALYs, combining actual years (axis $\mathrm{x}$ ) and dimensionless quality (axis y), are, in fact, semi-standardised measures

We can do the same with the dimension of time, assigning 0 to birth and 1 to lifetime expectancy. Continuing the example above, the dimensionless $\mathrm{l}$ is assigned to $80 \mathrm{y}$, the dimensionless 0.625 to $50 \mathrm{y}(50 \mathrm{y} / 80 \mathrm{y})$ and the dimensionless 0.375 to $30 \mathrm{y}(30 \mathrm{y} / 80 \mathrm{y})$. Thus, fully standardised QALYs $=$ SQALYs $=0.67 \times$ $0.625=0.41875$, and fully standardised DALYs $=$ SDALYs $=0.33 \times 0.625+1.00 \times 0.375$ $=0.58125$; that is, $41.875 \%$ of the life expected to be lived was actually lived and $58.125 \%$ was lost. Again SQALYs+SDALYs = $\mathrm{l}=100 \%=$ life expectancy.

These transformed to fully dimensionless standardised measures seem to be more understandable: SQALYs are the percentage of life lived, and SDALYs the percentage of life lost; as their sum equals 1, they are complementary. They do not measure life as lifetime; therefore they are not misleading. And thirdly they permit comparisons between countries, nations, sub-nations, etc, with different lifetime expectancy.

In contrast, we could of course unstandardise both axes, by assigning lifequality its real scale, but it remains to be discovered.

Department of Hygiene and Epidemiology, Medica School, University of loannina, 45110 loannina, Greece; idimolia@cc.uoi.gr

doi: 10.1136/jech.2003.014167

\section{References}

1 Murray CJL, Lopez AD. Global burden of disease study. Lancet 1997;349:1269-76, 1347-52, 1436-42, 1498-504

2 Arnesen T, Nord E. The value of DALY life: problems with ethics and validity of disability adjusted life years. BMJ 1999;319:1423-5.
3 Gold MR, Stevenson D, Fryback DG. HALYs and QALYs and DALYs, oh my: similarities and differences in summary measures of population health. Annu Rev Public Health 2002;23: 115-34.

\section{Previous trials of dissemination were identified}

Morrison et al examine the effect on questionnaire response of feeding back research findings to participants. ${ }^{1}$ As authors of the systematic review ${ }^{2}$ cited in their paper we would like to point out that we had in fact identified eight such randomised trials. ${ }^{3-10}$ The broad strategy under which these trials had been classified in our review was "nonmonetary incentives". We are currently updating our systematic review and have recently extended the search of databases to the beginning of 2003 and have contacted the authors of potentially eligible trials. A further two trials ${ }^{11} 12$ have been identified and the total of 10 trials have also been classified under the new strategy called "offer of research findings". These trials include a total of 13642 participants. When the results of these trials are pooled in a random effects meta analysis the odds ratio for response with research findings is 0.92 (95\% CI 0.75 to 1.11). Despite omitting to refer to these previous trials, Morrison et al were justified in conducting their trial: few of such trials have been health related and none has examined the effect of this intervention when participants are being resurveyed. However, even with the inclusion of their new trial in our systematic review, uncertainty about the effect of dissemination of research findings on questionnaire response remains.

The update to our systematic review now includes a total of 372 trials of methods to influence response to postal questionnaires classified under 98 strategies. Although many conclusions remain unchanged our updated review presents the definitive account of the evidence for which strategies may be used to improve response to postal questionnaires. The updated review will appear in the Cochrane Library later this year.

P Edwards, R Cooper Department of Epidemiology and Population Health London Schoo of Hygiene and Tropical Medicine London, UK

Correspondence to: Mr P Edwards, LSHTM, 49-51 Bedford Square, London WC1B3DP, UK phil.edwards@|shtm.ac.uk

\section{References}

1 Morrison DS, Thomson H, Petticrew M. Effects of disseminating research findings on response rates in a community survey: a randomised controlled trial. J Epidemiol Community Health 2003;57:536-7.

2 Edwards P, Roberts I, Clarke M, et al. Increasing response rates to postal questionnaires: systematic review. BMJ 2002:324:1183-5.

3 Dommeyer CJ. Does response to an offer of mail survey results interact with questionnaire interest? Journal of the Market Research Society 1985;27:27-38

4 Dommeyer CJ. Offering mail survey results in a lift letter. Journal of the Market Research Society 1989;31:399-408

5 Glisan G, Grimm JL. Improving response rate in an industrial setting: will traditional variables 
work? Southern Marketing Association Proc 1982;20:265-8.

6 Green KE, Kvidahl RF. Personalization and offers of results: effects on response rates. Journal of Experimental Education 1989;57:263-70.

7 Jobber D, Sanderson S. The effect of two variables on industrial mail survey returns. Industrial Marketing Management 1985; 14:119-21.

8 Kerin RA, Barry TE, Dubinsky AJ, et al. Offer of results and mail survey response from a commercial population: a test of Gouldner's norm of reciprocity. Proceeding of the American Institute of Decision Sciences 1981:283-5.

9 Mullner RM, Levy PS, Byre CS, et al. Effects of characteristics of the survey instrument on response rates to a mail survey of community hospitals. Public Health Rep 1982;97:465-9.

10 Powers DE, Alderman DL. Feedback as an incentive for responding to a mail questionnaire. Research in Higher Education 1982;17: 207-11

11 Thistlethwaite PC. The impact of selected mail response enhancement techniques on surveys of the mature market: some new evidence. Journal of Professional Services Marketing 1993:8:269-76.

12 Wiseman F. Methodological bias in public opinion surveys. Public Opinion Quarterly 1972;36:105-8.

\section{BOOK REVIEWS}

\section{Terrorism and public health: a balanced approach to strengthening systems and protecting the public}

Barry S Levy, Victor W Sidel, editors. (Pp 377; £35.00). Oxford University Press, New York, 2003. ISBN 0-19-515834-2

The preface states: "we believe this is the firs book that addresses terrorism from a public health perspective that is both comprehensive and balanced" (page xi). To a large extent, the book fulfils this promise, offering an informative, up to date, and highly readable summary of a broad range of public health issues that interface with the problem of international terrorism.

Part I has an introductory chapter followed by seven chapters examining public health challenges emerging after the September 11 th attacks. Four of these chapters summarise events in New York City, one covers the anthrax epidemic, one covers public health problems in war strapped Afghanistan, and one chapter offers an erudite and much needed account of the prospects for educating, informing, and mobilising the public.
Much of the material in part I is based on firsthand experience, and it is packed with information and insights that are unlikely to be found elsewhere. Part II covers conventional, biological, chemical, nuclear, and radiological terrorist weapons. Attention often focuses on arms control and its political underpinnings, but clinical aspects are also covered (though in too little detail to provide an important reference for clinicians). Part III addresses terrorism related "challenges and opportunities," with chapters aimed at public health systems, epidemiology, therapeutic interventions, research, environmental protection, civil liberties, roots of terrorism, and the promotion of international law. The comprehensiveness of the text suffers slightly from the lack of attention to methods of decontamination, structure and function of Incident Command Systems, and the coordination of disaster services under the Federal Emergency Management Agency.

The text is well "balanced" in the manner intended by the authors in so far as it nicely situates the need for terrorism prevention and response capabilities within the context of other, potentially competing public health needs, and it balances these needs against the imperative to avoid "inappropriate or hazardous responses to threats of future terrorism." On the other hand, there is little balance between competing viewpoints on ethical or policy issues. The book is structured by liberal cosmopolitan ideology-including numerous attacks on the Bush administration-with no attempt to fairly represent the range of credible, diverging opinions about the nature of justice or the intricacies of international collaboration and arms control.

G Trotter

\section{Dawning answers: how the HIV/ AIDS epidemic has helped to strengthen public health}

Ronald O Valdiserri, editor. (Pp 209; £29.92). Oxford University Press, 2003. ISBN 0-19. 514740-5

The HIV epidemic is still a great threat to public health, and the complexity of the infection regarding both biological and social aspects has challenged our skills to prevent its spread. The book presents a historica analysis to inform current policy development and to forecast the future, and describes some very important lessons learned during more than two decades with the HIV epidemic.
HIV has influenced the development and understanding of the use of multiple surveillance methods, integrated case based and behavioural surveillance, active collaboration between different public health stakeholders, and confidentiality and anonymity have become important issues.

Although sex may well be the most pleasurable human activity it is also very tabooed. The HIV risk reduction thus entails difficult behaviour changes, and the involvement of community members in this public health activity has become crucial. The adoption of "grey area" behaviours among at risk populations has led to the need for structural and individual level intervention. The HIV epidemic has shown the necessity of understanding surveillance data in their social context, for example, sex for drug. At the same time the "All or nothing" thinking opened to the principle of harm reduction.

The HIV epidemic has shown the importance of translating research results into active intervention and routine service delivery. HIV has had an impact on the organisation of prevention and care services and the public health planners are urged to consider the entire healthcare system, using all data available. Legal aspects and ethical issues, such as human rights, especially in relation to testing policy, named reporting and partner notification are very well discussed in the book.

The nine chapters are mainly dealing with the situation in the USA, however, the history in most western countries is similar and the book is absolutely worth reading for those interested in public health and in the HIV/ AIDS epidemic and policy. The public health challenges from infection diseases never stop.

E Smith

\section{CORRECTIONS}

doi: 10.1136/jech.2003.010553corr

An editorial error occurred in this paper by Dr Malinauskiene and others (2004;58:1315). The affiliation of $\operatorname{Dr} \mathrm{R}$ Malinauskas is Department of Psychology, Lithuanian Academy of Physical Education (this was omitted from the article).

doi: 10.1136/jech.2003.009589corr l

An editorial error occurred in this paper by Drs Mindell and Joffe (2004;58:103-13). In table 3, the age group for the first row of IHD admissions should be 0-64 (not 0-4). 